\title{
sciendo
}

\section{Time to act: discourse on time in crowdfunding for social entrepreneurship project}

\author{
Oana Mara STAN \\ University of Bucharest, Bucharest, Romania \\ mara.stan@sas.unibuc.ro \\ Mina FANEA-IVANOVICI \\ The Bucharest University of Economic Studies, Bucharest, Romania \\ mina.ivanovici@economie.ase.ro
}

PICBE |

\begin{abstract}
The context of public governance outsourcing social services and constantly downshifting its role creates the premises for increasing impact of crowdsourced social entrepreneurship and grassroots mobilization. The study envisions the innovative concept of social entrepreneurship by crowdfunding through a sports event, with Swimathon as study case, where most of Romanian NGOs are active to promote their calls for fundraising. Swimmer-participants are fundraisers who take on a challenge (e.g. swimming a target distance) with the aim to raise funds, in teams, for the causes they support. This fundraising event involves donors in a participative setting that combines short-term volunteering and crowdfunding. The research aims to understand practices by which crowdfunding projects grouped into categories navigate constructs on time. The ensuing research questions are as follows: What typology of time orientation do crowdfunding projects in the Romanian landscape of sports-oriented social entrepreneurship display? What do they shift, reshape, and build on in terms of time agency, time management and time empowerment? The current study seeks to uncover and chart patterns of timebound discursive strategies that aim to attract donors for crowdfunding projects in Romania. It brings forth questions of power and influence, by explaining and synthesizing the variety of manners in which trade-offs and synergies and modelled and mapped. The thematic analysis of fundraising calls for action is structured two-fold, namely: the denotative and the connotative dimension of time. The first component reveals time agency, time use and time management as keynote discursive trends, whereas the second reveals the following categories: time and emotion, quality time and time pressure. Metaphors of time used in the discourse over sustainability appeared coupled with pressure to intervene fast. Findings gathered by connotative discourse analysis induce the idea of grassroots mobilization and individual agency to the forefront, whereas social structures of institutional support are afforded background importance. The study ends with a discussion on implications of using time cues for emerging trends in the build-up process of Romanian crowdfunding projects.
\end{abstract}

Keywords: crowdfunding, time capital, time agency, fundraising, critical discourse analysis, quality time, grassroots mobilization.

\section{Introduction}

Crowdfunding as a collective financing model reveals the expanding significance of pro-social consumption patterns, in a context of collaborative arrangements based on mutual aid and local self-reliance (Burtch et al., 2014). This approach highlights the role of socialization of investor-minded consumers dubbed prosumers (Toffler, 1980). They participate in decisionmaking and action, inasmuch as they challenge the market to generate new ideas and reconfigure its existing design to accommodate needs of social entrepreneurship. 
The landscape of crowdfunding research is eclectic. The typically researched areas about crowdfunding as sociotechnical practice include the promotional campaign (Meyskens \& Bird, 2015), success predictors in fundraising (Calic \& Mosakowski, 2016; Kaartemo, 2017), the individual and organizational precursors of donating behavior (Palacios et al., 2016; Cecere et al., 2017), the functionality and the design of fundraising platforms, e.g. the impact on revenues of enabling privacy control mechanisms for donors' identity and contribution amount (Mataira et al., 2014). For instance, the visibility and traceability of supporters and their contributions in donation-based crowdfunding result in a relative leveling of donations, with peak and low-end sums tempered around middle-range values (Burtch et al., 2015; Kuppuswamy \& Bayus, 2017).

Research on content analysis of crowdfunding messages examines the cognitive and affective precursors of trustworthiness and determinants of project funding success (Veit Wohlgemuth \& Berger, 2016), innovation in the design of online technologies and social entrepreneurship outlets for crowdfunding platforms (Mollick, 2014), and decision-making models in relation to campaign characteristics (Lukkarinen et al., 2016). Moreover, recent studies unveil the role of government regulations, social networks and communities of support in connection to typologies of backers and rewards (Kshetri, 2015) in shaping niche investments, e.g. in alternative energies (Vasileiadou et al., 2016). Previous research on social trading conceptualizes crowdfunding through the lens of social-psychological theories such as: reasoned action, planned behavior and motivation-opportunity-ability model (Palacios et al., 2016), also pointing to the propensity towards emotional work and surface acting, as dimensions of artists' personalities (Davidson \& Poor, 2015; Davis et al., 2017). Another trending stream of research envisions the financial outlook on crowdfunding as risk capital and investment instrument for social business. From this vantage point, crowdfunding, in the form of crowd-lending and equity-based funding, receives attention as a continuity of business angel, venture capital and microfinance mechanisms that feed the social entrepreneurial evolution. Identifying and diversifying alternative sources of finance is yet another concern of the Council of the European Union (2014).

As crowdfunding becomes more widespread in Romania too, funders become themselves more discerning and selective among the multiplying options that place greater strain on their already limited financial resources. Hence, they are looking for objective criteria against which to assess the impact of proposed crowdfunding initiatives, in terms of sustainable value creation. The time-centric relevance system is assumed to function, for targeted audiences, as predictor for the success of such programs and hence it is expected to contribute to the effectiveness of crowdfunding campaigns. Small-scale social entrepreneurs are at risk for under-funding on account of market consolidation, with global NGOs gaining leverage and strengthening their competitive advantage at the expense of local initiative groups. Hence the latter have to look for alternative, more ingenious means to promote their messages across target audiences when traditional funding methods fail.

The trends in the framing discourse and the logic of social investment rationale capture the process by which social marketers (i.e. fundraisers) construct and reference time as rhetoric tool. The study aims to explore the cognitive schemas and culturally constructed rationalities of time scripts by critical discourse analysis. It is performed on two data streams: (1) fundraisers' communication present in project description and (2) first-person rhetoric included in team description and donors' feedback section. Ergo, the study integrates 
discursive interaction by examining multi-voice messages from diverse stakeholders: NGO representatives (fundraising marketers), team members (cause ambassadors) and supporters / backers (individual contributors). The theoretical backbone for this study explores the configuration of the sustainability discourse, connected to the coordinates of three intertwined streams of research concerning crowdfunding, resilient communities and social entrepreneurship. It also draws on the research directions in time and marketing, with a focus on the role of time in advertising social business.

\section{Literature review}

Research on time reveals the overarching pattern of time pressure when experiences merge with maximal intensification and densification. The time constraints characteristic of the $24 / 7$ society, time harassment, time compression and hunger for time are explored empirically through the lens of "a dialectic of resistance and accommodation" (Pickering 1995:22-23). Time has become the most strained, hence valued resource of all (Beck, 1992). John Urry (2000) discusses time acceleration and intensification in the postmodern society using the hologram metaphor which replaces the succession of linear time with the simultaneity of instantaneous "here and now", relying on evanescent experiences that disperse attention. The time capital refers to the total resources of productive (i.e. paid and unpaid, e.g. housework) and non-productive intervals (free or discretionary time) that an individual has available, in terms of assets convertible into other forms of capital (i.e. human, social and material) (Preda, 2013).

Quality time reflects the flow-like optimal experience that is intense, immersive, effortless, memorable and significant to the point that it causes timelessness: 'You merge with the activity, everything goes smooth, on automatic pilot, you contribute like you could go on and on, relentlessly' (Csikszentmihalyi, 1990, p. 5). Hence, quality time is described discursively as a state of memorable 'high' wherein everything goes smoothly and effortlessly. The flow experience is situated at the meeting point between high skills and high challenges where intrinsic motivation reaches its peak. Flow states imply a 'highly disciplined mental activity or strenuous physical exertion [wherein people] stop being aware of themselves as separate from the actions they are performing' (Csikszentmihalyi, 1990, p. 4). The author discusses mindful flow experiences that create a new reality based on intense flow experiences conductive of happiness. This is inspired by the etymology of 'ecstasy' in Greek, which means to stand at the side of something extraordinary and, by extrapolation, witness the fabulous side of everyday facts.

As realm of agency and empowerment, wherein individuals forge their pastimes and customize their subjective time experiences, time in itself is considered as "the key that opens the gateway to the treasures of self-determined life" (Beck, 1992, p. 212). Beck's argument resembles Flaherty's (2003, p. 11) concept of "time work", defined as "intrapersonal and interpersonal effort directed toward provoking or preventing various temporal experiences." Hence, each individual can exert agency over time in its performative function, by handling and negotiating time allocation practices with other social actors. These practices include the personalized control over duration, frequency, sequence or timing of each activity. By the interest invested in social ventures, crowdfunding marks a revitalization of the public arena by participative undertakings. The study posits that time cues contribute to the construction 
of the social marketing strategy on showcased crowdfunding platforms. These cues facilitate the donors' transition from awareness, to intention and afterwards to behavior.

As a broad notion and trending field of study, sustainability is widely conceptualized as the individual's or community's capacity to fulfill present-day requirements without jeopardizing next generations' needs (Rogers, 2015; Mejía-Dugand, 2016). Long-term viability and survivability are attributes of organizations that deploy "reliable operating systems, sufficient capacity, and multiple support streams" (Mataira et al., 2014, 238).Calic and Mosakowski (2016) found that donors assess project legitimacy by third-party endorsements, while the creativity of the campaign design mediates the relationship between the sustainability orientation and crowdfunding success.

Crowdfunding derives from crowdsourcing, in that it aims to attract and mobilize resources (in this case, mainly funds, but also support, buzz, word-of-mouth spreading) from 'the crowd' or the community (Meyskens \& Bird, 2015; Howe, 2006; Alderete, 2017). Resilience refers to a personal or collective ability to maintain consistency and cohesion in the face of change, especially adversity and shocks, by enacting coping and empowerment mechanisms (Adger, 2000). In this sense, time agency functions as personal resource for empowerment.

A necessary step forward to add explanatory force to the concept of "resilient community" would be to extend its boundaries, since resilience is often portrayed as "a middle-class niche pursuit for the ecologically minded" (Barr \& Devine-Wright, 2012, p. 531).

\section{Methodology}

With retrospective attention to emulating these established streams of research, the current study maps a future research line in discourse analysis over crowdfunding and the sustainability of social entrepreneurial ventures considered as prosumer capitalism (Ritzer \& Jurgenson, 2010). It analyzes Swimathon, the largest crowdfunding platform in Romania with regional coverage, to explore how time is marketed as shared resource that everyone can relate to, and customized as dimension of co-creative labor. To this purpose, it relies on the following inquiries:

1) How is time and the customization of temporal experiences treated discursively across crowdfunding discourse?

2) How is time framed and marketed, according to stakeholders' voice? What dimensions of time are illustrated in denotative and connotative meaning-making strategies?

3) How do crowdfunding projects navigate the challenge of reconciling antagonistic notions of sustainability of impact versus emergency of needed intervention? This is relevant because the call for help is now, but the effects of the required interventions are visible only in the long-run.

The study relies on critical discourse analysis to decipher crowdfunding stakeholders' meaning-making strategies. The basic assumption underlying this research is that language tells a story, as immersive rhetoric and performative framing mechanisms that pass along meaning while transfiguring it (Wooffitt, 2005). Appeals for action, project descriptions and members' comments are eventually storylines whose choice of wording is not in the least haphazard, but points to purpose and significance, as cultural affordance.

The stratified thematic analysis relies on grounded theory applied to the crowdfunding platforms of Swimathon Bucharest, Cluj and Iaşi. As such, it employs open 
coding to detect and categorize references to time for three discursive layers: 1 . appeal to action (fundraising call), 2. main stakeholders (crowdfunder-swimmers' call to action) and 3. secondary stakeholders: backers' messages (donors who accompany their financial contribution with a message to support the cause).

The concept of Swimathon originates from the UK and its objective remains to encourage amateurs to swim a target distance (between 400 and 5,000 meters), in teams, with the aim to raise funds for social enterprises.

For the case study the three most prominent foundations in terms of experience were selected (number of organized events: 9 in Cluj, 7 in Bucharest and Iaşi) and key performance outcomes (number of crowdfunded projects, raised funds), namely Bucharest, Cluj and Iaşi. Swimathon provides a hybrid form of crowdfunding: it is donation-based - donors are recruited among the social network of swimmers - and also reward-based in that it offers participants an experience of taking part in a swimming festival supported by the community. Swimathon builds donation mechanisms, it innovates crowdfunding means and promotes idea incubators for the respective cities and surrounding regions.

In Romania, beneficiaries who access crowdfunding through Swimathon are relatively low-profile local social ventures that are peripheral in terms of leverage and influence, compared to global players in the field of social entrepreneurship. This is evident in the target sums that range between EUR 1000 and 6000. Such thresholds are mostly aspirational and tentative, since the social venture receives the raised funds even if the target sum has not been reached.

\section{Results and discussions}

The majority of projects displayed on the three crowdfunding platforms under scrutiny include time references: 22 out of the 25 projects for Bucharest, 9 out of the 10 projects for Cluj and 18 out of the 28 projects for Iași.

\section{Time agency}

Time agency or the human 'in-built' capacity to customize temporal experiences emerges as prevailing motif in the discourse analysis of two sections: project descriptions and team members' messages. Discourse displays references to all dimensions of time agency, namely duration (e.g. "let's spend more time volunteering to assist sick children"), frequency ("they benefit from help doing homework on a weekly basis"; "each Thursday, no exceptions, we reunite to..."; "they benefit from weekly activities and from our recurrent support"; "monthly free-of-charge recovery therapy"; "they visit us for a hot meal on a daily basis"), sequence (e.g. "they first need a hot meal"; "to start the reforestation we first get approval from local authorities and afterwards we prepare the necessary equipment") and time allocation practices (e.g. "Let's make time to help others!") in the presentation of projects awaiting crowdfunding. As such, time agency, a.k.a. time work, relates to performing deliberate efforts to invest more time in social initiatives, and to contribute to increasing the frequency of wanted behavior (e.g. "by extending the number of days"; "children will be healthier, they will study better and the adults will be more easily employable"), while decreasing the incidence, frequency and duration of unwanted behavior (e.g. "we offer 
psychological support to shorten the period of denial and anger, until acceptance"; "we aim to decrease the number of hospitalization days and the incurring costs thereof").

Fundraisers strive to gain legitimacy and drive momentum by proving enduring commitment, e.g.: "We take part for the third consecutive year" and by providing factual details on the time budgets invested in their social pursuits, especially from the beneficiaries' point of view: "Each child spends an average of 4 days each day, 6 days per week at one of our two neighborhood Clubs". Most remarks about time are denotative, however there are also some connotative cues, for instance to the enduring sufferance that intended project beneficiaries have to overcome and to their resilience and will to survive: "Children with cancer take part in a marathon that they did not want to enroll in".

Messages from supporters are for the most part nominal, not anonymous, and they are directed towards a discourse on time work. By spending time at the benefit of others, donors assume the role of empowering change for a sustainable, objectively measurable impact. In this case, time agency focuses on the dimension of succession, in terms of acknowledging the role of prioritization skills: "To transform the society in which we live in, we first need to reform the system we learn by"; "We first need to think about what we can do for those less fortunate than us", "Their impact depends on our support". By and large, donors prove their capacity to render sense and purpose to the crowdfunding experience by discursive means of witnessable displays of kindness targeting the most vulnerable. The empowering effect of spending time for pro-social causes is in line with the findings of Kuppuswamy and Bayus (2017), who argue that donors will contribute as long as they believe that their own contribution will have an impact and tilt the scale in favor of the cause.

Time cues provided by swimmer-crowdfunders also bring forward orientation towards planning and data-driven anticipation: "this space became absolutely insufficient a few months ago. (...) In our new space we will be able to host approximately 35 persons per day and offer almost 10,000 free meals each year". Time references to sustainability include implicit suggestions to predictability, self-reliance and long-term reliability that shape the future, inserted in the following examples: "The future is in our hands"; "Together we draw the children's future", "the impact that this project can have on them in the long run", "afterwards the library will become self-sufficient", "this helps all of us and also our children to breathe a cleaner air and enjoy nature".

\section{Quality time}

Quality time represents the secondary motif, as per prevalence across the three discursive layers: project description, crowdfunders' accounts and donors' narratives. Discourse employs absolute time markers (e.g. "forever", "never", "always", "infinitely") to express emotional content that is borderless and universal. Time references allude to limitless love and hope: "I am delighted to join this project, as I always do in the case of children"; "the confidence that we can go on forever"; "they were never afraid to move forward"; "continue to donate, not only your money, but also your time and love for those who need them so much".

For swimmer-crowdfunders, time for fundraising is a special interval, set apart from daily constraints: "the possibility to take part in activities that they do not have access to in daily life"; "to offer kids (...) beautiful days". Quality time is about nurturing, memorable experiences: "We want to offer these poor kids an unforgettable holiday, an experience to 
remember as postcard memory in their soul". In this respect, time discourse promotes the creation and consolidation of resilient communities who spend meaningful time together and share memorable experiences in a cohesive, non-judgmental climate, endowed with a sense of belonging and affiliation.

\section{Time pressure}

Similar to quality time, time pressure serves as secondary motif as per prevalence across the three previously identified discursive layers. As in the case of time agency, time pressure refers to frequency: "They have a constant and compulsory need for daily therapies"; "It is a daily struggle", "The true superheroes are the children who fight with severe illness so hard each day", "Because of recurring lung infections they get hospitalized very frequently". Another component of time pressure refers to duration, e.g.: "The treatment is difficult to cope with in the long term", "social integration after healing is a long process", "faced with an implacable, lifelong diagnosis", "they could be evacuated anytime", "Don't think 'maybe' don't just 'try to'! Just do it: right here and now!". The need to act is stringent, and time discourse reflects the imperative strain to take decisive action immediately, as time is compressed, so as the possibility of intervention is limited: "The sooner he starts treatment, the better his chances of recovery".

This discursive strategy that stresses the sense of urgency and timing limitations applies especially to projects that target operable medical conditions and other social (charitable) projects, especially those introduced for the first time in the current edition of Swimathon, so without a previous history to draw on. The gravity of consequences of nonintervention and irreparable loss associated to useless time passage are other arguments belonging to the rhetoric of time pressure that first-time crowdfunding projects dwell on: "Each day that passes, without a child with special needs to be involved in the right therapies hinders recovery".

References to time are rhetorical tropes used with the persuasive purpose of convincing people to donate more. The time-oriented design of fundraisers' discourse customizes donors' experience along pre-established, as well as emerging lines of cognition and action. A recurring argumentative stream persuades donors to escape the traps of consumerism, become involved for the greater good and make efforts for long-term community development. Multi-voice discourse featuring on Swimathon platforms counteracts stereotypical, one-size-fits-all approaches and instead embraces decolonized diversity and contrasting views. It is a contextualized multi-stakeholder communication style that breaks away from the established hegemonic order of large-scale NGOs to accommodate scope for action in small social entrepreneurship projects.

This discursive style employs time as argument for the vocation of crowdfunding to fill institutional voids, where public authorities offer too little support or none at all. Time references provide proof of concept for social venture viability in the start-up phase and for its sustainability, in the consolidation and expansion phases. The time-centric signals of trustworthiness in project description focus on contextualization by a documented trackrecord of past success. Time serves as historicity landmark of progress for campaigns in the consolidation and expansion phases of crowdfunding appeals. Hence, recurring projects envision time for sustainability and resilience by a rational, more structured outlook on time as promoter of development. 
Conversely, for start-ups (first-time project proposals), the focus shifts towards the evanescent emotional dimensions of less structured, more "messy" and volatile time references to emergency and pressure for achieving harm alleviation. Hence, even if all crowdfunded projects are small-scale, low-profile and local in intervention, as per the mission of the Swimathon crowdfunding platforms, there is a segmentation between established projects and newly launched ones, from the approach to time. The former category use mostly time work and quality time cues, and the latter employs more the vocabulary of motives that belongs to time pressure. As such, we can conclude that the factor that counts more in times of choice for one of the three non-exclusive, but diverging discursive repertoires is the crowdfunding project's lifecycle, not regional aspects (disparities between Bucharest, Iaşi and Cluj) or the profiling of project types (i.e. environmental, educational, humanitarian, sports, cultural etc.).

\section{Conclusion}

Time-oriented discursive designs support social learning and intervention by exerting influence on resource allocation practices towards social entrepreneurship causes. Time cues underline the importance of local contexts for specific systems of discursive relevance built around sustainability and resilient communities. The contextualized time discourse on the Swimathon platform markets sustainability and expresses meaning-making within the crowdfunding process.

The strategies for time deployment present in the discourse of swimmers-fundraisers and backers attest to their belonging to the category of prosumers. Their perspective can be paraphrased in lay terms as such: "we repair what others damaged, we are on our own, we can only achieve results by ourselves, regulation brings no improvement and public governmentality is futile". This discursive line frames an individualistic reaction to the dilemma of collective action and society and Earth at large as our biggest externalities.

Prosumers' arguments are built around pivotal dimensions of time that wage war against the oversaturation and pervasiveness of consumerism, as one Swimathon donor framed it: "I'm happy I can make a difference with my money, not spend it on junk expensive stuff and get fat and miserable in the process". Strategies of identification with the crowdfunder self through time work references are thought of as seized opportunities for self-expression and autonomy. Also, time contributes to creating a donor-centric intrinsically rewarding experience by fostering a sense of belonging to a resilient community that combines empowerment, solidarity and enjoyment.

Usually overlooked and undervalued as too general and abstract a notion, time carries in its discursivity the potential for change. As empirical evidence suggests in the current study, this is because time integrates two apparently dichotomist characteristics: it is both a common denominator that people can identify with and relate to across their everyday practices, and the highest customizable resource, as time use style that marks each individual's unique personality.

Time is a notion that the target audience of potential donors is highly sensitive to, although probably unaware of its implicit influence as call for action in social entrepreneurship. Findings gathered by connotative discourse analysis induce the idea of grassroots mobilization and individual agency to the forefront, whereas social structures of institutional support are afforded background importance. Time discourse provides 
persuasive strength to project descriptions by the supplied cues for inclusiveness, legitimation and participation.

The tension between established and emerging crowdfunding initiatives reflects also a dialectics on time agency and sustainability, as opposed to immediacy of intervention. In the design of crowdfunding messages, time functions as credential for objectivity, but also as emotional hint, hence its versatility as discursive resource that accelerates the rate of conversion of reputational resources into financial resources. Time can therefore magnify the rate of conversion of admirers and would-be donors into actual contributors by facilitating the transition from intention, to decision and actual conduct. This is noteworthy as strategic advantage is an era of diminishing resources and proliferation of crowdfunding appeals. There is arguably a tension between social (niche) and commercial (mainstream) marketing that stems from a reversed exchange. Whereas traditional marketing employs financial resources aiming to transform them into reputation, social marketing uses timebuilt reputation to gain financial resources.

\section{References}

Adger, W.N. (2000). Social and ecological resilience: are they related? Progress in Human Geography, 24 (3), 347-364.

Alderete, M.V. (2017). The age of prosumerism: some micro-economic analysis. Journal of Theoretical and Applied Electronic Commerce Research, 12(3), 1-12.

Barr, S., \& Devine-Wright, P. (2012). Resilient communities: sustainabilities in transition. Local Environment, 17(5), 525-532.

Beck, U. (1992). Risk society. Towards a new modernity. London, UK: Sage Publications.

Burtch, G., Ghose, A., \& Wattal, S. (2015). The hidden cost of accommodating crowdfunder privacy preferences: a randomized field experiment. Management Science, 61(5), 949-962.

Burtch, G., Ghose, A., \& Wattal, S. (2014). Cultural differences and geography as determinants of online prosocial lending. MIS Quarterly, 38(3), 773-794.

Calic, G., \& Mosakowski, E. (2016). Kicking off social entrepreneurship: how a sustainability orientation influences crowdfunding success. Journal of Management Studies, 53(5), 738-767.

Cecere, G., Le Guel, F., \& Rochelandet, F. (2017). Crowdfunding and social influence: an empirical investigation. Applied Economics, 49(57), 5802-5813.

Council of the European Union (2014). Draft conclusions of the Council and the Representatives of the Governments of the Member States, meeting with the Council, on a Work Plan for Culture (2015-2018). Retrieved from http://data.consilium.europa.eu/doc/document/ST-16094-2014-INIT/en/pdf. Csikszentmihalyi, M. (1990). Flow: the psychology of optimal experience. Retrieved from http://www.ode.state.or.us/opportunities/grants/nclb/title_i/a_basicprograms/ schoolimprovement/transformation7flow.pdf.

Davidson, R., \& Poor, N. (2015). The barriers facing artists' use of crowdfunding platforms: personality, emotional labor, and going to the well one too many times. New Media \& Society, 17(2), 289-307. 
Davis, B.C., Hmieleski, K.M., Webb, J.W., Coombs, J.E. (2017). Funders' positive affective reactions to entrepreneurs' crowdfunding pitches: the influence of perceived product creativity and entrepreneurial passion. Journal of Business Venturing, 32(1), 90-106.

Flaherty, M. (2003). Time work: customizing temporal experience. Social Psychology Quarterly, 66(1), 17-33.

PICBE |

1171

Fundaţia Comunitară București (2018). Annual reports on Swimathon. Retrieved from https://fundatiacomunitarabucuresti.ro/2016/08/05/swimathonbucuresti/.

Fundaţia Comunitară Cluj (2018). Annual reports on Swimathon. Retrieved from http://www.fundatiacomunitaracluj.ro/.

Fundația Comunitară Iași (2018). Annual reports on Swimathon. Retrieved from https://www.fundatiacomunitaraiasi.ro/fondurile/fondul-swimathon/.

Howe, J. (2006). The rise of crowdsourcing. Wired Magazine, 14(6), 1-4.

Kaartemo, V. (2017). The elements of a successful crowdfunding campaign: a systematic literature review of crowdfunding performance. International Review of Entrepreneurship, 15(3), 291-318.

Kshetri, N. (2015). Success of crowd-based online technology in fundraising: an institutional Perspective. Journal of International Management, 21(2), 100-116.

Kuppuswamy, V., \& Bayus, B.L. (2017). Does my contribution to your crowdfunding project matter? Journal of Business Venturing, 32(1), 72-89.

Lukkarinen, A., Teich, J., Wallenius, H., \& Wallenius, J. (2016). Success drivers of online equity crowdfunding campaigns. Decision Support Systems, 87, 26-38.

Mataira, P., Morelli, P., Matsuoka, J., \& Uehara-McDonald, S. (2014). Shifting the paradigm: new directions for non-profits and funders in an era of diminishing resources. Social Business, 4(3), 231-244.

Mejía-Dugand, S. (2016). The evolution of Sweden's urban sustainability marketing tool: a comparative study of two major international events. Journal of Urban Technology, 23(2), 65-80.

Meyskens, M., \& Bird, L. (2015). Crowdfunding and value creation. Entrepreneurship Research Journal, 5(2), 155-166.

Mollick, E. (2014). The dynamics of crowdfunding: an exploratory study. Journal of Business Venturing, 29(1), 1-16.

Palacios, M., Martinez-Corral, A., Nisar, A., \& Grijalvo, M. (2016). Crowdsourcing and organizational forms: emerging trends and research implications. Journal of Business Research, 69(5), 1834-1839.

Pickering, A. (1995). The mangle of practice: time, agency, and science. Chicago, US: University of Chicago Press.

Preda, M. (2013). Time capital and social gravity: two new concepts for sociology of time. In Pirani, B., Smith, T. (Eds.), Body and time: bodily rhythms and social synchronism in information flood. Newcastle upon Tyne, UK: Cambridge Scholars Publishing.

Ritzer, G., \& Jurgenson, N. (2010). Production, consumption, prosumption: the nature of capitalism in the age of the digital 'prosumer'. Journal of Consumer Culture, 10(1), $13-36$.

Rogers, J. (2015). Sustainability storylines and the politics of distribution. The International Journal of Sustainability in Economic, Social, and Cultural Context, 11(1), 13-27. 
Toffler, A. (1980). The third wave. New York, US: Bantam.

Urry, J. (2000). Sociology beyond societies: mobilities for the twenty-first century. London, UK: Routledge.

Vasileiadou, E., Huijben, J., \& Raven, R. (2016). Three is a crowd? Exploring the potential of crowdfunding for renewable energy in the Netherlands. Journal of Cleaner Production, 128, 142-155.

Veit Wohlgemuth, E., \& Berger, M. (2016). More than just financial performance: trusting investors in social trading. Journal of Business Research, 69(11), 4970-4974.

Wooffitt, R. (2005). Conversation analysis and discourse analysis. A comparative and critical introduction. London, UK: Sage Publications. 